\title{
KELOID; \\ PRODUCTION OF KELOID ANIMAL MODEL \\ ambabar@gmail.com
}

1. MBBS, FCPS, FRCS, PhD (Surgery)

Head of the Department of Surgery Postgraduate Medical Institute Ameeruddin Medical College Lahore General Hospital Lahore, Pakistan

2. MBBS, FCPS, FRCP, FRCPath, PhD Head of the Department of Pathology

Incharge Experimental Research Laboratory

University of Health Sciences,

Lahore, Pakistan

Correspondence Address:

Prof. Dr. Dr. Abdul Mannan Babar

15, Younas Shaheed Street, Islam

Gunj

Lahore, Pakistan

ambabar@gmail.com

Article received on:

19/05/2016

Accepted for publication:

$31 / 08 / 2016$

Received after proof reading:

10/09/2016

\section{Prof. Dr. Abdul Mannan Babar ${ }^{1}$, Prof. Dr. Abdul Hannan Nagi}

ABSTRACT: Keloids and hypertrophic scars are basically an overabundance of fibrosis in cutaneous healing process. Unfortunately, keloids are only found in human beings. So far no successful animal model of keloid has been reported. Objectives: To produce an animal model of keloid. Main Outcome Measure: Animal model of keloid. Design: Prospective quasiexperimental trial. Setting: Department of Pathology and Experimental Research Laboratory, University of Health Sciences, Lahore, Pakistan. Duration: One year. Sample Size: Twelve albino animals i.e. three mice, three rats, three Guinea pigs, and three rabbits. Sampling Technique: Simple Convenience. Material and Methods: Three different techniques of keloid production were used. First animal of each species was given skin punch excision only; second was given Transforming Growth Factor Beta 1 injection only; and third was given Transforming Growth Factor Beta 1 injection followed by skin punch excision. Results were noted at four weeks. Results: Out of twelve animals, keloid was produced only in one rabbit (ear) which was given Transforming Growth Factor Beta 1 injection followed by skin punch excision. Conclusion: Keloid animal model can be produced in rabbit ear by giving Transforming Growth Factor Beta 1 injection followed by skin punch excision of ventral surface skin.

Key words: $\quad$ Cicatrix, Hypertrophic; Guinea Pig; Keloid; Model, Animal; Mouse; Rabbit; Rat; Transforming Growth Factor Beta 1.

Article Citation: Babar AM, Nagi AH. Keloid; Production of keloid animal model. Professional Med J 2016;23(9):1157-1162. DOI: 10.17957/TPMJ/16.3535

\section{INTRODUCTION}

Keloids and hypertrophic scars are basically an overabundance of fibrosis in cutaneous healing process. Keloids are benign cutaneous fibroproliferative tumours. Hypertrophic scars are similar in nature, but do not grow into normal tissue (Philandrionos). ${ }^{1}$ Keloids and hypertrophic scars are generally sequelae of wounds, whether surgical or traumatic. They can also follow minor abrasions, or needle wound, like injection, or may be spontaneous. They form three months to many years after injury. They are very variable in size; small injuries may cause big lesions (Sidgwick). ${ }^{2}$ Exact aetiology of keloids and hypertrophic scars is not known. However many factors have been labelled as aetiological/risk factors These can be intrinsic i.e. race, genetics, age, sex, site, tension, direction, hormones, syndromes, hypertension, autoimmunity, and spontaneous; or extrinsic i.e. piercing, tattooing, epilation, buns, bites, vaccination, infection, irritation, inflammation, sutures, foreign body, and drug induced (Babar). ${ }^{3}$
Keloids are only found in human beings. This is the main hindrance for scientific research on keloids, as direct research on human bring is not feasible, and is also unethical. Therefore research on keloids has mostly been clinical, with limited evidence base. So far no successful animal model of Keloids has been produced. Therefore efforts are going on to establish an animal model of Keloids (Ramos). ${ }^{4}$ The other mode of research is tissue culture model. Fibroblasts are isolated form human keloid tissue, and cultured in artificial media. Different experiments are done on these fibroblasts to study aetiology, pathogenesis, and treatment of keloids. However, it is found out that fibroblasts are not the only culprits in keloidogenesis; other cells and biochemical are as important in keloid formation (Babar). ${ }^{3}$

Tissue culture model is more appropriate for the study of pathophysiology of wound healing and keloid formation, while animal model is more 
suitable for the study of treatments of keloids (Ramos). ${ }^{4}$ Though cell culture model is useful in study of mechanism of action of drugs for keloid, yet animal model is required to study safety of drug prior to its application to human beings (Hillmer). ${ }^{5}$ According to Ramos, ideal animal model must have characteristics of hypertrophic scar in histological, biochemical, immunological, molecular, and clinical behaviour. ${ }^{4}$

There are many types of animal models of hypertrophic scars produced so far.

\section{A. Implanted Animal Models}

1. Hypertrophic scar or keloid implant in immunodeficient mouse (Shetlar). ${ }^{6}$

2. Hypertrophic scar or keloid implant in immunodeficient rat (Shetlar). ${ }^{6}$

3. Hypertrophic scar or keloid implant in immune privileged cheek pouch of hamster (Hochman). ${ }^{7}$

4. Hypertrophic scar or keloid implant in chick embryo (Szabo). ${ }^{8}$

5. Hypertrophic scar production by implantation of full thickness skin on back of immunodeficient mouse (Yang). ${ }^{9}$

B. Induced Animal Models

6. Hypertrophic scar production by chemically induced injury in Guinea pig (Aksoy). ${ }^{10}$

7. Hypertrophic scar production in specific anatomic site (ear) of rabbit (Morris, Li, Zhu). ${ }^{11-13}$

8. Hypertrophic scar production in deep dermal wound of pig (Zhu). ${ }^{14}$

9. Hypertrophic scar production by transection of medial cruciate ligament in dog (Matthews). ${ }^{15}$

10. Hypertrophic scar production by induction with polyvinyl sponge in albino rat (Kelly). ${ }^{16}$

11. Hypertrophic scar production by induction of chronic inflammation granulomata in rat (Bazin). ${ }^{17}$

\section{Implanted+Induced Animal Models}

12. Hypertrophic scar production by implantation of skin, and later burning it, on back of nude mouse (Robb). ${ }^{18}$
D. Organotypic Animal Models

13. Hypertrophic scar production by engineered tissue implantation in immunodeficient mouse (Wang \& Luo). ${ }^{19}$

14. Hypertrophic scar production by engineered tissue implantation in immunodeficient rat (Wang \& Luo). ${ }^{20}$

\section{E. Tissue Culture Models}

15. Tissue culture model of keloid fibroblasts (Robinson). ${ }^{21}$

16. Tissue culture (serum free) model of keloid fibroblasts (Koch). ${ }^{22}$

F. Tissue Engineering Models

17. Tissue engineering model of keloid fibroblast populated collagen lattice (Garner, Kuhn). ${ }^{23,24}$

18. Tissue engineering model of keloid fibroblasts \& keratinocytes populated collagenglycosaminoglycan lattice (Lim, Supp). ${ }^{25,26}$

\section{G. Biochemical Models}

19. Biochemical model of collagen of rat (Ketchum). ${ }^{27}$

20. Biochemical model of collagen of mouse (Ketchum). ${ }^{27}$

However, no workable model of keloid has been produced so far. Novelty in authors' technique is use of Transforming Growth Factor Beta 1. There is an important function of Transforming Growth Factor Beta 1 in healing of wounds; it is a potent chemotactic factor for fibroblasts and stimulates them to produce major extracellular matrix components including collagen. Transforming Growth Factor Beta 1 is produced by macrophages as well as extracellular matrix. Transforming Growth Factor Beta 1 acts by activation of fibroblasts, leading to accelerated collagen production. Transforming Growth Factor Beta 1 is produced in higher quantities in keloids, and keloid fibroblasts respond to lower quantities of Transforming Growth Factor Beta 1 than normal fibroblasts. Addition of exogenous Transforming Growth Factor Beta 1 activates fibroblasts, thereby increasing production of collagen, and formation of keloids. 
The purpose of this study was to produce a successful and workable animal model of keloids.

\section{MATERIALS \& METHODS}

It was a prospective quasi-experimental trial carried out at Department of Pathology and Experimental Research Laboratory, University of Health Sciences, Lahore, Pakistan. It was of one year duration. Sample consisted of twelve albino laboratory animals i.e. three mice, three rats, three Guinea pigs, and three rabbits. These animals were taken from breeding facility/animal house of the University. Sampling technique was simple convenience.

Mice and rats were anaesthetised with diethyl ether in a closed glass jar using open-drop method. Guinea pigs and rabbits were anaesthetized with combination of Ketamine $(75 \mathrm{mg} / \mathrm{kg}$ intraperitoneal), and Xylazine $(15 \mathrm{mg} / \mathrm{kg}$ intraperitoneal) injections. In case of mice, rats, and guinea pigs, dorsolateral area of trunk was used for production of lesions, after clipping of hairs with an electric clipper. In case of rabbits, ventral surface of ear was used. Area was disinfected with sterilized gauze soaked with normal saline, and alcohol prep pad before production of lesion.

Three different techniques of Keloid production were used. First animal of each species underwent skin punch excision only; second underwent Transforming Growth Factor Beta 1 injection only; and third underwent Transforming Growth Factor Beta 1 injection followed by skin punch excision. Transforming Growth Factor Beta 1 injection (Santa Cruz Biotechnology, 10410 Finnell Street
Dallas, Texas 75220, USA; Tel +1-8004 57-3801; email scbt@scbt.com; URL www.scbt.com) 100 pg in $0.1 \mathrm{ml}$ water, prepared in insulin syringe was used, and waited for 1 minute before skin punch excision.

Skin punch excision was carried out by a $4 \mathrm{~mm}$ skin biopsy punch (Acu-Punch; Acuderm Inc., 5370 NW, 35 Terrace, Ft. Layderdale, FL 33309, USA; Tel +1-8003 27-0015; URL www.acuderm. com). It is a pre-sterilized prepacked single-use punch biopsy forceps, whose circular sharp edge acts as a knife, and with pressure at its back end, as well as circular movements, cuts a disc of skin. When disc of skin is cut, it contracts naturally due to presence of elastic fibers, and becomes elevated from underlying subcutaneous tissue. This loose connective tissue is cut with a sharp pointed scissors. Any bleeding is controlled with pressure with a cotton gauze for a few minutes.

Wounds were dried with sterilized gauze and electric hot air dryer. Wounds were dressed with hydrocolloid dressing. Routine post-operative care was taken. No analgesics or sedatives were required. No antibiotics were given. Routine wound care was taken. Dressing was allowed to fall off spontaneously. Results were noted at four weeks.

\section{RESULTS}

All animal were examined at four weeks. Out of twelve animals, Keloid was produced only in one rabbit (ear) which was given Transforming Growth Factor Beta 1 injection followed by skin punch excision (Table-I).

\begin{tabular}{|l|l|l|l|l|}
\hline Sr. No. & Animal & Technique & Height of Healed Wound (mm) & Keloid Formed? \\
\hline 1 & Mouse 1 & Punch Excision & 0.10 & No \\
\hline 2 & Mouse 2 & TGFB1 Injection & 0.00 & No \\
\hline 3 & Mouse 3 & Punch Excision + TGFB1 Injection & 0.20 & No \\
\hline $\mathbf{4}$ & Rat 1 & Punch Excision & 0.13 & No \\
\hline 5 & Rat 2 & TGFB1 Injection & 0.00 & No \\
\hline 6 & Rat 3 & Punch Excision + TGFB1 Injection & 0.19 & No \\
\hline $\mathbf{7}$ & Guinea Pig 1 & Punch Excision & 0.07 & No \\
\hline $\mathbf{8}$ & Guinea Pig 2 & TGFB1 Injection & 0.00 & No \\
\hline $\mathbf{9}$ & Guinea Pig 3 & Punch Excision + TGFB1 Injection & 0.15 & No \\
\hline 10 & Rabbit 1 & Punch Excision & 0.23 & No \\
\hline 11 & Rabbit 2 & TGFB1 Injection & 0.00 & No \\
\hline $\mathbf{1 2}$ & Rabbit 3 & Punch Excision + TGFB1 Injection & $\mathbf{1 . 3 5}$ & Yes \\
\hline & Table-I. Comparison of Keloid Formation with different Techniques in different Animals \\
\hline
\end{tabular}


It was a clinically significant keloid (Figure-1). It was hard in consistency, dome-shaped, red in colour, with smooth surface. It was devoid of hairs. The keloid was followed-up for one year, and it was were present even at that time. However, it was not possible to ask about symptoms of keloids from rabbits.

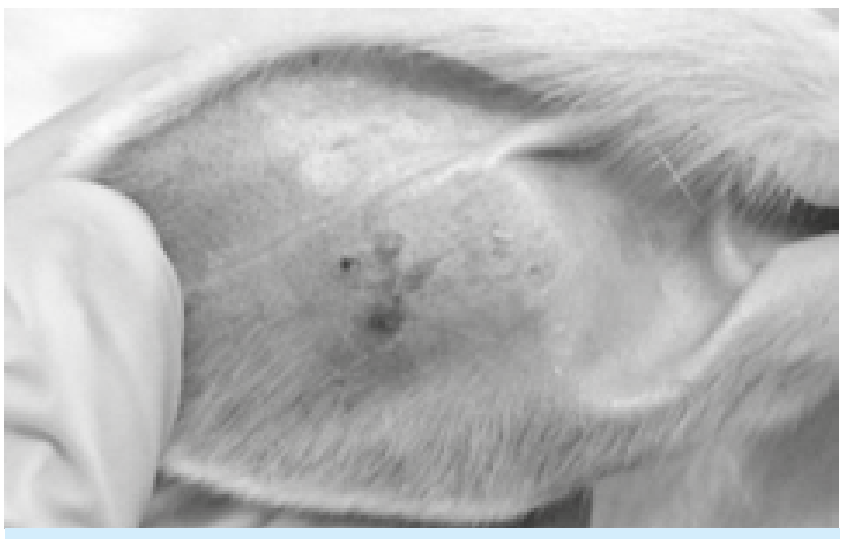

Figure-1. Keloid Animal Mode produced in Rabbit Ear

On gross examination, excised keloid was hard in consistency, and could be palpated as definite nodule between thumb and fore-finger. It had red and smooth surface. On cutting the specimen, there was gritty feeling. Cut surface was pale in colour. Histopathology of keloid showed homogeneous, brightly eosinophilic, irregularly distributed, glassy, hyalinized collagen. Fibroblasts were scant, and oriented in direction of collagen (Figure-2).

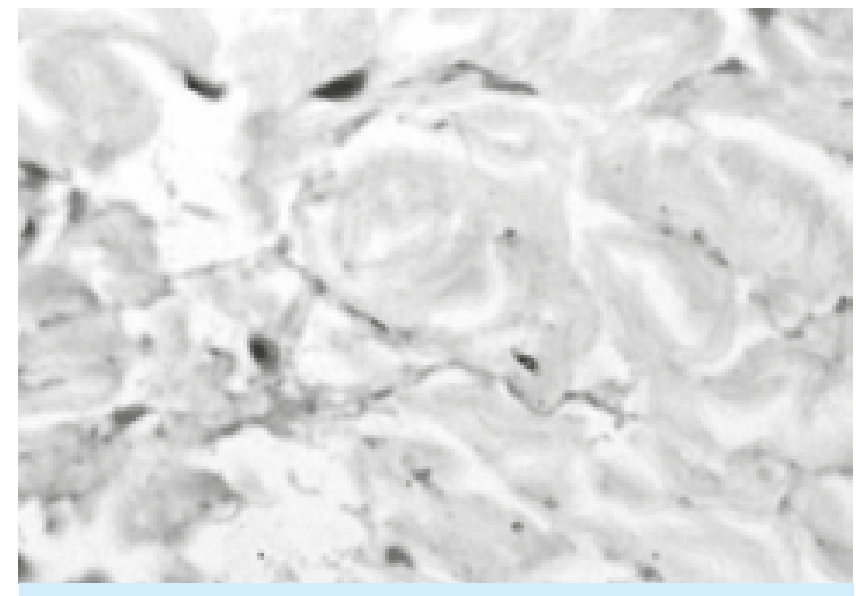

Figure-2. Histopathology of Keloid Animal Model

\section{DISCUSSION}

Keloids are only found in human beings. So far no successful animal model of Keloids has been reported. Therefore efforts are going on to establish an animal model of Keloids. Our effort is one such effort. This is the first animal model of keloid ever produced, as proved by clinical, gross, and microscopic examinations. Previous models could only produce hypertrophic scars, and not keloids. Previous efforts to produce keloid animal models are discussed below.

Regarding implanted animal models, Szabo et al in 1971 performed explantation of human keloid in chick embryo, and studied effects of hydrocortisone, ascorbic acid, and hyaluronoglucosaminidase on it. ${ }^{8}$ Shetlar et al in 1985 produced animal model of hypertrophic scars in immunodeficient mice by implantation of human keloid and hypertrophic scar tissue. Keloids maintained the original morphological patterns and glycosaminoglycan distributions for 60 days after implantation. They proposed that this model would allow morphologic, biochemical and therapeutic studies. ${ }^{6}$ Hochman et al in 2005 from Brazil reported Keloid heterograft in hamster cheek pouch as an animal model. This pouch is an immune privileged site and there is no rejection of explanted tissue. ${ }^{7}$ Yang et al in 2007 reported development of a new hypertrophic scar model by implanting full thickness human skin on immunodeficient mice. Ninety percent of these mice developed hypertrophic scars. ${ }^{9}$

Regarding induced animal models, Kelly in 1964 implanted polyvinyl sponge in albino rats to produce fibrosis, and studied effect of Quinones on it. ${ }^{16}$ Bazin etal in 1975 experimentally developed granulation tissue of chronic inflammation in rats, which contained embryonal collagen. They proposed these granulomata as a model of human hypertrophic scar. ${ }^{17}$ Morris et al in 1997 developed rabbit ear hypertrophic scar model. They produced this model by $6 \mathrm{~mm}$ excisional wounds on ventral surfaces of rabbit ears. They treated these scars with triamcinolone acetonide. ${ }^{11} \mathrm{Li}$ et al in 2001 reported establishment of experimental animal model for hypertrophic scar on rabbit ears by creating round and rectangular wounds. They noted that rectangular wound produced more 
hypertrophy than round wounds. They studied effects of Transforming Growth Factor Beta 1 and Interferon gamma on these scars. ${ }^{12}$ Aksoy et al in 2002 produced hypertrophic scar animal model in albino Guinea pigs. They performed circular excision of dorsal skin followed by excision of panniculus carnosus, and coal tar application. ${ }^{10}$ Matthews et al in 2004 reported that medial cruciate ligament transection in dogs produced a scar-like mass on medial side of knee joint. This mass mimicked clinical fibrosis, and might be used as model of hypertrophic scars. ${ }^{15}$ Zhu et al in 2008 suggested need of research to study relationship of anatomy of rabbit ear and creation of hypertrophic scar. They noted that best sites for producing hypertrophic scars were medial margin of middle and inferior part of ear. ${ }^{13}$

Regarding implanted+induced model, Robb et al in 1987 applied human skin to back of nude mice, and burned it after a month, leading to hypertrophic scar formation. They also applied meshed skin graft and achieved contracture. ${ }^{18}$

Regarding organotypic animal models, Wang and Luo in 2005, and again in 2013 established animal model of hypertrophic scars by tissue engineering technique. They used complex of keloid fibroblasts and poly-lactic-co-glycolic acid (PLGA) copolymer. These were implanted in subcutaneous pouches of immunodeficient mice. Implants increased in size from days 30 to 180. Increased amounts of fibroblasts and collagen were there in these implants at day 180 having histology similar to human keloid. These fibroblasts had increased amount of rough endoplasmic reticulum. ${ }^{19,20}$

Regarding tissue culture models, Robinson et al in 1951 published a report on use of tissue culture model to study keloid pathology ${ }^{21}$. This study remained dormant for decades. Koch et al in 1997 reported use of serum-free keloid fibroblast culture for keloids, in order to eliminate role of growth factors found in serum. His results were comparable to those of serum-based models. ${ }^{22}$

Regarding tissue engineering models, Garner et al in 1995 and Kuhn et al in 2001 devised tissue engineering models using keloid fibroblastpopulated collagen lattices. ${ }^{23,24}$ Tissue engineering model of keloid fibroblasts \& keratinocytes populated collagen-glycosaminoglycan lattice was produced by Lim et al in 2002. ${ }^{25}$ Supp et al in 2012 also reported hypertrophic scar induction using tissue engineering method. They cut this engineered sheet and studied wound healing on it. Keloid cells responded to injury by increasing extracellular matrix production. ${ }^{26}$

Regarding biochemical models, Ketchum et al in 1967 performed in vitro studies to see effect of hydrocortisone, triamcinolone acetonide, and microbial collagenase on mature rat collagen. ${ }^{27}$

\section{CONCLUSION}

Keloid animal model can be produced in rabbit ear by giving Transforming Growth Factor Beta 1 injection followed by skin punch excision of ventral surface skin.

Copyright (C) 31 Aug, 2016.

\section{REFERENCES}

1. Philandrianos C, Kerfant N, Jaloux C, Jr., Martinet L, Bertrand B, Casanova D. Les cicatrices cheloides (premiere partie): une pathologie de la cicatrisation cutanee \{French\} [The keloid scars (part one): a pathology of cutaneous wound healing]. Ann Chir Plast Esthet. 2015. doi: 10.1016/j.anplas.2015.09.005.

2. Sidgwick GP, McGeorge D, Bayat A. A comprehensive evidence-based review on the role of topicals and dressings in the management of skin scarring. Arch Dermatol Res. 2015. 307:461-77.

3. Babar AM. Keloids and Hypertrophic Scars (unpublished work). 2015. Lahore: University of Health Sciences.

4. Ramos ML, Gragnani A, Ferreira LM. Is there an ideal animal model to study hypertrophic scarring? J Burn Care Res. 2008 29:363-8.

5. Hillmer MP, MacLeod SM. Experimental keloid scar models: a review of methodological issues. J Cutan Med Surg. 2002. 6:354-9.

6. Shetlar MR, Shetlar CL, Hendricks L, Kischer CW. The use of athymic nude mice for the study of human keloids. Proc Soc Exp Biol Med. 1985. 179:549-52.

7. Hochman B, Vilas Boas FC, Mariano M, Ferreiras LM. 
Keloid heterograft in the hamster (Mesocricetus auratus) cheek pouch. Acta Cir Bras. 2005. 20:200-12.

8. Szabo $E$, Ladanyi $P$, Kiss FA. Untersuchungen an explantierten Keloidgewebe \{German\} [Studies on explanted keloid tissue]. Arch Dermatol Forsch 1971. 241:75-85.

9. Yang DY, Li SR, Wu JL, Chen YQ, Li G, Bi S, et al. Establishment of a hypertrophic scar model by transplanting full-thickness human skin grafts onto the backs of nude mice. Plast Reconstr Surg. 2007. 119:104-11.

10. Aksoy MH, Vargel I, Canter IH, Erk Y, Sargon M, Pinar A, et al. A new experimental hypertrophic scar model in guinea pigs. Aesthetic Plast Surg. 2002. 26:388-96.

11. Morris DE, Wu L, Zhao LL, Bolton L, Roth SI, Ladin DA, et al. Acute and chronic animal models for excessive dermal scarring: quantitative studies. Plast Reconstr Surg. 1997. 100:674-81.

12. Li H, Liu J, Xia W. 建立和實驗動物模型的應用增生性 瘢痕 \{Chinese\} [Establishment and application of experimental animal model for hypertrophic scar]. Zhonghua Zheng Xing Wai Ke Za Zhi = Chinese J Plast Surg. 2001. 17:276-8.

13. Zhu GY, Xu B, Cai JL. 免耳解剖結構和建立增生性 瘢痕動物模型之間的相關性的實驗研究 \{Chinese\} [Experimental research of correlation between anatomy structure of rabbit ear and creating hypertrophic scar animal model]. Zhonghua Zheng Xing Wai Ke Za Zhi = Chinese J Plast Surg. 2008. 24:216-9.

14. Zhu KQ, Engrav LH, Gibran NS, Cole JK, Matsumura $\mathrm{H}$, Piepkorn $\mathrm{M}$, et al. The female, red Duroc pig as an animal model of hypertrophic scarring and the potential role of the cones of skin. Burns. 2003. 29:649.

15. Matthews JL, Chung M, Matyas JR. Indirect injury stimulates scar formation-adaptation or pathology? Connect Tissue Res. 2004. 45:94-100.

16. Kelly EW, Jr. Tetrahydroxyquinone (Thq) effects on sponge implants in the albino rat. Arch Pathol. 1964. 77:317-23.

17. Bazin S, Bailey A, Le Lous M, Nicolétis C, Delaunay
A. Collagène polymorphisme dans les cicatrices humaines \{French\} [Collagen polymorphism in human scars]. C R Acad Sci Hebd Seances Acad Sci D. $1975.281: 1447-9$.

18. Robb EC, Waymack JP, Warden GD, Nathan P, Alexander JW. A new model for studying the development of human hypertrophic burn scar formation. J Burn Care Rehabil 1987. 8:371-5.

19. Wang HB, Luo SK. 組織工程痒痕疙㾂的動物模型的構建 \{Chinese\} [Construction of animal models of keloid by tissue engineering]. Di Yi Jun Yi Da Xue Xue Bao = Acad J Fir Med Coll PLA. 2005. 25:815-9, 832.

20. Wang HB, Luo SK. Establishment of an animal model for human keloid scars using tissue engineering method. J Burn Care Res. 2013. 34:439-46.

21. Robinson DW, Corbett E, Hamilton TR. Some observations on connective tissue growth and tissue culture in relation to keloid formation; a preliminary report. Surg Forum. 1951. 505-10.

22. Koch RJ, Goode RL, Simpson GT. Serum-free keloid fibroblast cell culture: an in vitro model for the study of aberrant wound healing. Plast Reconstr Surg. 1997. 99:1094-8.

23. Garner WL, Rittenberg $\mathrm{T}$, Ehrlich HP, Karmiol S, Rodriguez JL, Smith DJ, et al. Hypertrophic scar fibroblasts accelerate collagen gel contraction. Wound Repair Regen. 1995. 3:185-91.

24. Kuhn MA, Moffit MR, Smith PD, Lyle WG, Ko F, Meltzer $D D$, et al. Silicone sheeting decreases fibroblast activity and downregulates TGFbeta2 in hypertrophic scar model. Int J Surg Investig. 2001. 2:467-74.

25. Lim IJ, Phan TT, Bay BH, Qi R, Huynh H, Tan WT, et al. Fibroblasts cocultured with keloid keratinocytes: normal fibroblasts secrete collagen in a keloidlike manner. Am J Physiol Cell Physiol. 2002. 28:C212-22.

26. Supp DM, Glaser K, Hahn JM, McFarland KL, Boyce ST. Abnormal responses of keloid tissue to wounding identified using in vitro model system. Eplasty. 2012. 12:e19.

27. Ketchum LD, Robinson DW, Masters FW. The degradation of mature collagen: a laboratory study. Plast Reconstr Surg. 1967. 40:89-91.

\section{AUTHORSHIP AND CONTRIBUTION DECLARATION}

\begin{tabular}{c|l|l|l|} 
Sr. \# & \multicolumn{1}{|c|}{ Author-s Full Name } & Contribution to the paper & Author=s Signature \\
\hline 1 & Prof. Dr. Abdul Mannan Babar & Original Author \\
\hline 2 & Prof. Dr. Abdul Hannan Nagi & Original Author & \\
\hline
\end{tabular}

